Proceedings

\title{
Towards Energy Citizenship for a Just and Inclusive Transition: Lessons Learned on Collaborative Approach of Positive Energy Districts from the EU Horizon2020 Smart Cities and Communities Projects ${ }^{\dagger}$
}

\author{
Rosamaria Olivadese 1,*, Beril Alpagut ${ }^{2}$, Beatriz Pineda Revilla ${ }^{3}$, Jeroen Brouwer ${ }^{1}$, \\ Vasiliki Georgiadou ${ }^{4}$, Alexander Woestenburg ${ }^{1}$ and Mark van Wees ${ }^{3}$ \\ 1 TNO, Strategic Analysis and Policy Department, Anna van Buerenplein 1, 2595 DA The Hague, \\ The Netherlands; jeroen.brouwer@tno.nl (J.B.); alexander.woestenburg@tno.nl (A.W.) \\ 2 Demir Enerji, Smart Cities Department, Kosuyolu Cad. Halili Sk. No.7, Kadikoy/İstanbul 34718, Turkey; \\ balpagut@demirenerji.com \\ 3 Urban Governance \& Social Innovation, Centres of Expertise Urban Technology, Amsterdam University of \\ Applied Sciences, Amstelcampus, Weesperzijde 190, 1097 DZ Amsterdam, The Netherlands; \\ b.pineda.revilla@hva.nl (B.P.R.); m.t.van.wees@hva.nl (M.v.W.) \\ 4 TNO, Monitoring \& Control Services Department, Anna van Buerenplein 1, 2595 DA The Hague, \\ The Netherlands; vasiliki.georgiadou@tno.nl \\ * Correspondence: rosa.olivadese@tno.nl \\ + Presented at the Sustainable Places 2020, Online, 28-30 October 2020; Available online: \\ https://www.sustainableplaces.eu/. \\ Published: 6 January 2021
}

\begin{abstract}
To achieve the "well below 2 degrees" targets, a new ecosystem needs to be defined where citizens become more active, co-managing with relevant stakeholders, the government, and third parties. This means moving from the traditional concept of citizens-as-consumers towards energy citizenship. Positive Energy Districts (PEDs) will be the test-bed area where this transformation will take place through social, technological, and governance innovation. This paper focuses on benefits and barriers towards energy citizenships and gathers a diverse set of experiences for the definition of PEDs and Local Energy Markets from the Horizon2020 Smart Cities and Communities projects: Making City, Pocityf, and Atelier.
\end{abstract}

Keywords: positive energy districts (PED); energy citizenship; smart cities and communities; energy democracy; local energy market; peer-to-peer energy trading platforms; collaborative approach; green deal; clean energy package

\section{Introduction}

To achieve the "well below 2 degrees" targets of the Paris Agreement and the United Nations Sustainable Development Goals (UN SDGs 7, 8, 11, 13), Europe has put in place a set of policies to foster the transition. The Clean Energy Package and the just enacted Green Deal foresee Europe as an integrated carbon neutral ecosystem where a fair and prosperous society lives. In these documents, citizens are at the heart of the decarbonization pathway to ensure a fair and inclusive transition towards carbon neutrality, securing that no one and no region is left behind. Hence, the transition towards a sustainable and climate-neutral society will not only require substantial investments across Europe but also the involvement of the relevant stakeholders from public and private sectors as investors, providers, designers, policymakers as well as all the EU citizens as prosumers, energy 
traders, organization members, and participatory designers. The transition from fossil fuels towards a carbon-neutral economy poses a lot of challenges that are not only technological but also economic, social, and of governance. Nowadays, more than $60 \%$ of people live in cities, which will increase by up to $80 \%$ by 2050 . At the same time, cities contribute to $70 \%$ of our world economy and while they cover only $2 \%$ of the total land on Earth, they consume $60 \%$ of the total energy and generate about $70 \%$ of Greenhouse Gases (GHG) emissions and waste [1]. In the energy transition process, cities need to answer three main questions: (1) how to best harmonize and mainstream climate policy across sectors, (2) how to choose and integrate low-carbon technologies, and (3) how to ensure citizens and businesses buy in [2]. Until now, smart cities have been evaluated mostly within the energy, mobility, and ICT domains, while integrated sustainable urban planning and societal engagement are also highly relevant for designing and implementing smart cities. Positive Energy Districts (PEDs) can be seen as the foundation of a highly efficient and sustainable route to progress beyond the current urban transformation roadmaps [3].

JPI Urban Europe [4] defines PED as "energy-efficient and energy-flexible urban areas or groups of connected buildings which produce net-zero greenhouse gas emissions and actively manage an annual local or regional surplus production of renewable energy. They require the integration of different systems and infrastructures, and the interaction between buildings, users, regional energy, mobility, and ICT systems, while securing the energy supply and a good life for all in line with social, economic, and environmental sustainability". These are projects on the local energy transition and infrastructure, urban regeneration, as well as moving towards more energy-conscious behavior [5]. Technological developments are now providing many more opportunities for a decentralized energy system, which can very well be organized in a democratic manner. Citizen cooperatives and local authorities can play a crucial role here by developing public-civil partnerships [6]. By building a good connection between the different stakeholders and engaging citizens, they become partners in the transition, they understand, trust, use, and feel ownership of the integrated energy and mobility solutions offered in their district. This could bring in around $45 \%$ of all EU households producing their own renewable energy by 2050 [6].

This paper focuses on benefits and barriers towards energy citizenships (Section 2) and gathers a diverse set of experiences and lessons learned on the collaborative approach for the definition of Positive Energy Districts (PEDs) and Local Energy Markets from the Horizon2020 Smart Cities and Communities projects: Making City, Pocityf, and Atelier (Section 3).

\section{Energy Citizenship: Benefits and Barriers}

In order to accelerate the energy transition, socio-economic-cultural and political considerations need to be acknowledged. In the traditional market approach, citizens are involved in energy production without sharing mechanisms, therefore investing-for their own benefit as passive consumers. To achieve carbon neutrality, a new ecosystem needs to be defined where citizens become more active, co-managing with relevant stakeholders, the government, and third parties. The notion of "energy citizenship" is born in this context where citizens evolve from being just consumers. Pushing the responsibility for the energy transition onto the citizen-as-consumer actually minimizes the role of citizens as agents of change, resulting in disempowered and disconnected citizens [7]. The current neoliberal discourse feeds the idea of the energy consumer whose responsibility for the energy transition is reduced to investing in innovative energy technologies and purchasing energyefficient devices, mostly associated with the home sphere. This discourse is based on the construct of individuals as homo economicus who are only motivated to change their behavior if presented with the right financial incentives. As a result, scenarios of inequality and exclusion arise, leaving behind those who lack the means to "contribute" or to "participate" in the energy transition through changes in their economic behaviors. The risks of this "material-based energy citizenship" [8] needs to be carefully considered to avoid excluding economically less privileged citizens or those who live in less technologically advanced areas while at the same time avoiding how "the privileged 'greenwash' non-sustainable lifestyles through expensive toys" [8]. 
A shift towards energy citizenship requires a move beyond individualistic approaches in order to include collective and inclusive spaces for participation and engagement. This way, households and communities can decide and act upon their own energy production and consumption, not only within the dwelling but also including other dimensions of their lifestyle that demand energy such as mobility, food consumption, and free-time activities. Low-carbon communities are an example of these collective spaces that aim at providing new contexts for action [9]. These communities can be place-based [10], linked to certain geographical boundaries (cities, municipalities, districts, neighborhoods, etc.) but also, they can be interest-based when members share a common interest [11]. Digital communities are also rapidly emerging in the last decade providing collective spaces to reflect and participate in the energy transition [12]. Moving towards energy citizenship implies to stop seeing energy as a commodity and to start acknowledging energy "as an ecological resource and as a social necessity, subject to collective decision-making" [7].

Other examples of collective action associated with energy citizenship are opening up windows of opportunity for energy citizenship to flourish (deliberative democracy, grassroots innovations, and social movements) [13-15]. However, most citizens are still locked into their routinized unsustainable behaviors. To realize the citizen-as-consumer to energy citizen transition, multiple barriers need to be overcome, specifically institutional, infrastructural, financial, and regulatory. From an infrastructural perspective, a strong role of the government is required to overcome some of the current structural barriers. Investing in new energy infrastructures and providing legislations that enable innovative governance structures can bring citizens one step closer to the desired energy citizenship [7]. Besides, it is crucial to work on an inclusive notion of energy citizenship and to understand what energy citizenship means for different groups of citizens. Not all citizens are at the same stage in their transition towards becoming an energy citizen. Uncovering the dynamics behind different types of energy citizenship transitions might shed some light on how to better support citizens and collectives in their own journeys. The following case studies aim at illustrating this diversity of energy citizens.

\section{Use Cases: Pathway to Energy Citizenship in SCC Projects}

\subsection{MAKING CITY, the Cases of Oulu and Groningen}

MAKING CITY (http://makingcity.eu/) is one of the first revolutionary projects of the EU funded Horizon 2020 Smart City and Communities call that supports the shift from single, unintegrated, simple "building" based interventions into Positive Energy Blocks and Districts concepts in order to reach energy and climate targets which will lead to an integrated energy planning. This shift now achieves more importance to empower citizens since they are gaining new and innovative roles than just being consumers. Within the traditional system, citizens were trying to be involved in energy production without sharing mechanisms, therefore investing for their own benefit. For citizens, the issue of energy is usually not a standalone issue but connected to the overall improvement of wellbeing, both on the level of individual homes as on the level of neighborhoods or districts.

For Oulu and Groningen, being the lighthouse cities of MAKING CITY, a key challenge for PED development is to understand how citizens consider the topic of energy as related to their own lives and other local challenges such as public green, climate adaptation, mobility, quality of their houses, parking, etc. The City of Oulu Interaction Plan for 2019-2021 states that "everyone feels to be heard. This must be equal and respectful, so that it does not make a difference who is saying". People may in practice value others differently, but the direction is clear, and the starting point is not bad either. A key challenge, thus, is to create a shared story of the future of a neighborhood or district that people recognize and value. The City of Oulu conducted an operations model [16] that is founded on community bridges and forums in the major areas, open to everyone. Coordinators of public engagement of residents of the municipality act as the introducers and secretaries of the activities. Usually, a resident of a major area acts as the chair of the activities. In the community bridges, forums and other joint events in the area people can participate and interact with public actors and others. The aim is to reform services in municipal resident- and customer-oriented manner as well as to have 
the residents involved in planning and decision-making concerning their residential area and services. The city supports the regional involvement and operation of municipalities through regional operating grants and by providing facilities in different areas of Oulu. Participatory budgeting, which involves residents reflecting and deciding where their financial resources are to be spent, has also been piloted in Oulu.

On the other hand, Groningen's goal is to be $\mathrm{CO}_{2}$ neutral by 2035. In order to achieve this goal, heating houses by means of natural gas must end. In order to explore what might be the best solution, the municipality has conducted a study, which resulted in three possible scenarios: all-electric, a warm water grid, and a hybrid solution using electricity and green gas. The city of Groningen has developed a "district energy approach" [17] aligned with this vision and it is a labor-intensive process, complementing with a fully bottom-up behavior that facilitates groups of enthusiastic residents to do as much on their own as possible by the integration of the "cooperative approach" that provides a central role for the citizens thriving network of community energy groups, which can be a basis for community building, in the development of the district (energy) plans and PEDs. This cooperative approach operating on a local level (districts) encourages the inhabitants for becoming energy citizens, overcoming most of the barriers mentioned in Section 2 of this paper. The participation process is carried out by and for the local citizens, supported by the local cooperative. During this process, citizens learn how to execute the strategy themselves. In this way, the knowledge stays within the community, increasing the social trust and community attachment and belonging and, as a result, the potential impact is increased.

\subsection{ATELIER, the Case of Amsterdam}

ATELIER (https://smartcity-atelier.eu/) aims to demonstrate Positive Energy Districts in Bilbao and Amsterdam acting as lighthouse cities. In the Buiksloterham area (Amsterdam), a number of demonstrator projects (building complexes and blocks) were selected based on their unique innovative character and ambitions to contribute to becoming a Positive Energy District (PED). Not each and every building or block is energy positive in itself; hence, it relies partly on an innovative distribution network that will enable effective and secure distribution and trading of renewable energy flows over (day, week, and annual) time. For making this distribution and trading between demonstration projects (buildings and blocks) possible, an innovative Local Energy Market (LEM) platform will be established to enable the virtual trading and sharing among the various projects in the PED Buiksloterham. Two contributing projects have installed smart grids for enabling the sharing of RES among owners and participants already. Both projects are exemplary for bottom-up initiatives, where participants are taking the lead in initiating, designing, planning, and realizing these neighborhoods for working and living.

De Ceuvel, a temporary allocation of a plot in Buiksloterham to a creative business community, with a number of building units in place, that all have a particular solar energy generation capacity, next to a need for heating (heat pumps) and appliances' energy use. The separate building-units are all interconnected via a smart grid enabling sharing, distribution, and eventually also trading of energy flows. In order to stimulate the community to maximize the local use of solar power being generated on the project, instead of exporting to the public grid, in 2017, a crypto-currency named Jouliette was introduced and is operational at De Ceuvel (https://deceuvel.nl/en/). Via blockchain technology, the participants of De Ceuvel on the smart grid are receiving the currency for the production of energy and can trade this among the others for the exchange of energy.

Schoonschip, the first energy-positive floating community, consisting of over 30 residential houses being built as arks, floating on water. More than 40 families collaboratively planned, designed, and built (as a Collectively Self Organized housing community) this floating community on the water in the Buiksloterham district, in line with high ambitions on the use of materials, energy, and waste management (https://schoonschipamsterdam.org/\#site_header). The floating houses are all connected to a self-owned local smart grid, allowing the local distribution and sharing of energy flows, for the use of the heat pumps and household appliances. Energy flows are actively monitored 
and managed through software for optimization of the local grid balance, for instance, by remotely operating the heat pumps for managing the peak loads.

According to the Dutch law on electricity, no active trading among private residents is allowed. Through an exemption construct under the supervision of the Dutch ministry, this particular community is allowed, within restrictions, to privately distribute, share, and trade (including establishing payment schemes and service fees, etc.) the local energy flows and manage the one-off connection with the public grid.

In the wider context of the PED Buiksloterham, two new real estate projects are under development and will join the above-described projects in forming the Local Energy Market platform, where virtual energy trading and monetization will be implemented on the larger (PED) scale. An important element for further analysis will be how the commitment and behavior of the future homeowners and/or tenants will be in the newly developed projects, given that the new development projects will be realized by professional real estate developers, and will not start off from a community initiative, nor reflect early involvement of the end-users.

\subsection{POCITYF}

Citizens' local communities lie at the heart of POCITYF (https://pocityf.eu/). POCITYF brings together technology providers, grid operators, policymakers and local communities to collectively work on integrated innovative solutions across the built environment, energy infrastructure, and emobility. The goal is to enact PEDs while ensuring widespread adoption and market uptake of best practices that promote an open and collaborative ecosystem towards accelerating energy transition and sustaining long-term benefits. With the participation of Alkmaar (NL) and Evora (PT) as lighthouse cities, along with their six historically renowned fellow cities geographically distributed across Europe, special attention is given to ensuring that solutions are in harmony with cultural elements of the urban and natural landscape. Communities in such areas feel especially connected to their city's cultural heritage; so, any solution should respect and work together or even enhance and preserve such elements.

In this context, citizens need effective tools for their voices to be heard and perhaps even more importantly, to become key stakeholders within the decision-making process. One such solution to be incorporated and demonstrated within POCITYF pilot areas is a peer-to-peer (P2P) energy trading platform. P2P energy trading may then be perceived as a market-based community mechanism that would become one of the pillars of the actual embodiment of the spirit behind Citizen Energy Communities (CECs) [18]. Indeed, regulatory and policy advancements around CECs can have a "break or make" effect for excessively collaborative integrated solutions to become viable in the longterm. On the surface, P2P energy trading empowers citizens to feel in control of their own energy flexibility and to valorize it in a direct way; thusly providing another route for CECs to reshape the energy market landscape along with introducing new products and services. Nevertheless, P2P energy trading can also be leveraged to enhance a community's social cohesion by stacking nonenergy related services that have been identified as bringing added value to its members and further nudge people to adjust their behavior [19].

In particular, at Evora, the P2P use case is implemented as "[...] a transactive layer allowing the operation of local market between selected buildings, also rewarding citizens' sustainable actions and investments and underpinning the injection of PV generation from PV plants in the surroundings of the three Positive Energy Blocks". The P2P platform, in this case, adopts a holistic approach based on "tokens rewarding schemes to promote sustainable behaviors" [20]. Such tokens may be awarded via an overarching citizen engagement platform that stands as a reference point for community members to be informed, interact, and co-create the new vision for their neighborhood and city [21].

At Alkmaar, P2P is also explored as a market-based community mechanism on top of "[...] an implementation of a City Energy Management System (CEMS) where the users and owners of the buildings can buy or sell energy to each other and sell flexibility [...], while smart charging and vehicle-to-grid (V2G) systems for the electric vehicles (shared cars and buses) will also be connected to the energy trading platform" [20]. Especially for setting the objectives of this implementation, apart 
from the municipality of Alkmaar and its citizens, the housing corporations involved in the demo areas of Van de Veldelaanflat (high-rise apartment block) and Bloemwijk (newly built neighborhood) are specifically and actively participating in the decision-making process. Through the housing corporations, the residents and members of the local communities are being engaged via the so-called Customer Journey method that helps stakeholders to position the citizens centrally and guide them through the different steps towards adopting energy transition best practices and becoming an ambassador of the change [22].

\section{Conclusions and Remarks}

Each of the three projects described in this paper involves citizens in different ways. In MAKING CITY, strong city visions that people recognize and value are the first steps to buy citizens in. A bottom-up approach is used on the district level to create and share knowledge, to develop district energy plans and PEDs. In ATELIER, smart grids are owned by the community and operate within the exemption construct that allows distributing, sharing, and trading RES between private residents themselves, and with other entities in these communities as well. In POCITYF, P2P energy trading platforms are developed to allow citizens to become key stakeholders within the decision-making process. It empowers citizens to feel in control of their own energy flexibility and valorize it in a direct way.

From these pioneer PED projects, the enormous innovation potential of a combined approach towards physical energy transition investments and societal engagement can be counted as a first lesson. Intensified participatory processes, encourage partners that are relatively new to the table to traditionally established partners to seek integrated, collective solutions for the urban energy transition. Currently, many European cities are exploring, shaping, and formalizing policies that will structure their approaches and actions towards energy citizenship. From a knowledge perspective, we do see that targeted knowledge development on three topics would especially help cities and their transition partners to further operationalize the potential synergies of a combined approach towards technological and social challenges:

- Participation and engagement should be considered as multi-scalar and multi-level paths,

- The public interest of energy citizenship legitimates public actions and public tool choices,

- A quantified substantiation of the added value of the integrated planning claim.

Author Contributions: Conceptualization, R.O., B.A.; methodology, R.O., B.A., V.G., J.B., B.P.R.; investigation, R.O., B.A., V.G., J.B., B.P.R., A.W.; writing-original draft preparation, R.O., B.A.; writing-review and editing, R.O., B.A., V.G., J.B., B.P.R., A.W., M.v.W.; project administration, R.O., B.A. All authors have read and agreed to the published version of the manuscript.

Funding: The projects have received funding from the European Union's Horizon 2020 research and innovation program under the following Grant Agreements: No. 824418 (MAKING CITY), No. 864374 (ATELIER) No. 864400 (POCITYF).

Acknowledgments: The authors would like to thank the partners involved in the projects and the local ecosystems of all involved Lighthouse cities for their on-going support and collaboration.

Conflicts of Interest: The authors declare no conflict of interest. The content of the paper reflects only the authors' view. The European Commission is not responsible for any use that may be made of the information contained therein.

\section{References}

1. Borsboom-van Beurden, J.; Kallaos, J.; Gindroz, B.; Costa, S.; Riegler, J. Smart City Guidance Package. In $A$ Roadmap for Integrated Planning and Implementation of Smart City projects. Norwegian University of Science and Technology/European Innovation Partnership on Smart Cities and Communities; Faculty of Architecture and Design, Norwegian University of Science and Technology: Trondheim, Norway, 2019.

2. Fuso Nerini, F.; Slob, A.; Ericsdotter Engström, R.; Trutnevyte, E. A Research and Innovation Agenda for Zero-Emission European Cities. Sustainability 2019, 11, 1692, doi:10.3390/su11061692. 
3. Alpagut, B.; Montalvillo, C. MAKING-CITY D4.1-Methodology and Guidelines for PED Design; MAKING CITY Project Report, Grant Agreement No. 824418, Submitted to the European Commission; 2019; under review (accessible at Results \& Publications-Making City).

4. JPI Urban Europe/SET Plan Action 3.2. White Paper on PED Reference Framework for Positive Energy Districts and Neighbourhoods, 2020. Available online: https://jpi-urbaneurope.eu/ped/ (accessed on 15 October 2020).

5. Jaubin, J.; Ahlers, D.; Crombie, D.; Krangsås, S.G.; Massink, R.; Ozdek, E.; Peeters, L.; Renger W.J.; Sangiuliano, M. Citizen Engagement Solution Booklet; EU SCIS Smart Cities Information System: 2020 (accessible at Citizen Engagement I Smartcities Information System (smartcities-infosystem.eu)).

6. Holemans, D.; Van de Velde, K. Citizens Energy: Making Energy Democracy Happen; Green European Foundation: Brussels, Belgium, 2019.

7. Lennon, B.; Dunphy, N.P.; Sanvicente, E. Community acceptability and the energy transition: A citizens' perspective. Energy Sustain. Soc. 2019, 9, 35, doi:10.1186/s13705-019-0218-z.

8. Ryghaug, M.; Skjølsvold, T.M.; Heidenreich, S. Creating energy citizenship through material participation. Soc. Stud. Sci. 2018, 48, 283-303.

9. Heiskanen, E.; Johnson, M.; Robinson, S.; Vadovics, E.; Saastamoinen, M. Low-carbon communities as a context for individual behavioural change. Energy Policy 2010, 38, 7586-7595, doi:10.1016/j.enpol.2009.07.002.

10. Peters, M.; Fudge, S. Motivating Individual Carbon Reduction through Local Government-led Community Initiatives in the UK: The Role of Local Government as an Agent of Social Change. RESOLVE Working Paper, University of Surrey, Guildford, UK, April, 2008. Available online: http://resolve.sustainablelifestyles.ac.uk/sites/default/files/RESOLVE_WP_04-08.pdf (accessed on 14 October 2020).

11. Davoudi, S.; Dilley, L.; Crawford, J. Energy consumption behaviour: Rational or habitual? DisP Plan. Rev. 2014, 50, 11-19, doi:10.1080/02513625.2014.979039.

12. Pineda Revilla, B. Shaping energy norms in digital communities: The contribution of online discussion boards to questioning energy needs in Amsterdam. Energy Res. Soc. Sci. 2020, 67, 101586, doi:10.1016/j.erss.2020.101586.

13. Chilvers, J.; Longhurst, N. Participation in Transition(s): Reconceiving Public Engagements in Energy Transitions as co- Produced, Emergent and Diverse. J. Environ. Policy Plan. 2016, 18, 585-607, doi:10.1080/1523908X.2015. 1110483.

14. Hoffman, S.M.; High-Pippert, A. From private lives to collective action: Recruitment and participation incentives for a community energy program. Energy Policy 2010, 38, 7567-7574, doi:10.1016/j.enpol.2009.06.054.

15. Kunze, C.; Becker, S. Collective ownership in renewable energy and opportunities for sustainable degrowth. Sustain. Sci. 2015, 10, 425-437, doi:10.1007/s11625-015-0301-0.

16. Rinne, S.; Uusimäk, I.M.; Matinheikki, S.; Määttä, A; Autio, M.; Kosunen, H.; Hirvonen-Kantola, S.; Louis, J. MAKING-CITY D2.23 - New Citizens' Engagement Strategies in Oulu; MAKING CITY Project Report, Grant Agreement No. 824418, Submitted to the European Commission, 2020; under review; (accessible at Results \& Publications - Making City).

17. Joep Broekhuis, J.; Kort, J.; Tjahja, C. MAKING-CITY D3.24-New citizens' Engagement Strategies in Groningen; MAKING CITY Project Report, Grant Agreement No. 824418, Submitted to the European Commission, 2020; under review; (accessible at Results \& Publications-Making City).

18. Official Journal of the European Union. DIRECTIVE (EU) 2019/944 OF THE EUROPEAN PARLIAMENT AND OF THE COUNCIL of 5 June 2019 on Common Rules for the Internal Market for Electricity and Amending Directive 2012/27/EU; Official Journal of the European Union: Brussels, Belgium, 2019.

19. Huitema, G.; Veen van der, A.; Georgiadou, V.; Vavallo, M.; Garcia, M.A. Demand Response Optimization in Buildings and Energy Communities, a Case in Value Stacking. Multidiscip. Digit. Publ. Inst. Proc. 2020, $65,7$.

20. European Commission, Innovation and Networks Executive Agency. Grant Agreement POCITYF No. 864400; European Commission: Brussels, Belgium, 2019.

21. Gonçalves, L.; Bănică, B.; Patrício, L. Teixeira, J. D4.1: POCITYF Citizen Engagement Plan; POCITYF Project Report, Grant Agreement No. 864400; 2020; under review; (accessible at Resources-POCITYFPOCITYF). 
22. de Koning, N.; Kooger, R.; Hermans, L.; Tigchelaar, C. Natural Gas-Free Homes: Drivers and Barriers for Residents; Report P12006; TNO: The Hague, The Netherlands, 2019.

Publisher's Note: MDPI stays neutral with regard to jurisdictional claims in published maps and institutional affiliations.

(c) 2021 by the authors. Licensee MDPI, Basel, Switzerland. This article is an open access article distributed under the terms and conditions of the Creative Commons Attribution (CC BY) license (http://creativecommons.org/licenses/by/4.0/). 